\title{
The innovative viscoelastic CP ESP cervical disk prosthesis with six degrees of freedom: biomechanical concepts, development program and preliminary clinical experience
}

\author{
Jean-yves Lazennec $^{1} \cdot$ Alain Aaron $^{2} \cdot$ Olivier Ricart $^{3} \cdot$ Jean Patrick Rakover $^{4}$
}

Received: 19 August 2015/Accepted: 21 August 2015/Published online: 4 September 2015

(c) The Author(s) 2015. This article is published with open access at Springerlink.com

\begin{abstract}
The viscoelastic cervical disk prosthesis ESP is an innovative one-piece deformable but cohesive interbody spacer. It is an evolution of the LP ESP lumbar disk implanted since 2006. CP ESP provides six full degrees of freedom about the three axes including shock absorbtion. The prosthesis geometry allows limited rotation and translation with resistance to motion (elastic return property) aimed at avoiding overload of the posterior facets. The rotation center can vary freely during motion. The concept of the ESP prosthesis is fundamentally different from that of the devices currently used in the cervical spine. The originality of the concept of the $\operatorname{ESP}^{\circledR}$ prosthesis led to innovative and intense testing to validate the adhesion of the viscoelastic component of the disk on the titanium endplates and to assess the mechanical properties of the PCU cushion. The preliminary clinical and radiological results with 2-year follow-up are encouraging for pain, function and kinematic behavior (range of motion and evolution of the mean centers of rotation). In this series, we did not observe device-related specific complications, misalignment, instability or ossifications. Additional studies and longer patient follow-up are needed to assess longterm reliability of this innovative implant.
\end{abstract}

Jean-yves Lazennec

lazennec.jy@wanadoo.fr

1 Pitié Salpétrière Hospital, UPMC, Paris, France

2 FHI, Quimper, France

3 Kirchberg Hospital, Luxembourg, Luxembourg

4 Clinique du Pré, Le Mans, France
Keywords Cervical disk prosthesis - Artificial disk · Viscoelastic disk replacement - Cervical spine mobility . CP ESP - Rotation center - Degenerative cervical disk

\section{Introduction}

Anterior cervical discectomy and fusion (ACDF) is a proven intervention for patients with radiculopathy and myelopathy. A major concern related to the treatment of cervical degenerative disk disease and spondylosis with ACDF is the issue of adjacent segment degeneration [1].

Radiographic evidence of adjacent-level disease (ALD) has been reported to occur in as many as $92 \%$ of patients at 5-year follow-up [2]. Hilibrand et al. [3] calculated a $2.9 \%$ annual risk of symptomatic ALD; survivorship analysis projected that a $25.6 \%$ of the patients who underwent an ACDF would develop symptomatic ALD within 10 years after. There is clinical evidence to support the postsurgical nature of adjacent segment disease. Goffin et al. [2] were able to demonstrate a similar rate of ALD in younger patients with trauma compared with older patients with degeneration following anterior cervical arthrodesis.

The concept that adjacent levels need to compensate for loss of motion in the fused segment is supported by biomechanical studies. Cadaveric testing has demonstrated the finding that arthrodesis generally results in increased adjacent-level intradiscal pressures [4], and statistically significant changes in adjacent-level motion compared with arthroplasty under the same experimental conditions [5]. Studies additionally reveal that the degree of lordosis achieved during fusion significantly alters adjacent-level range of motion [6] and that in some cases, segmental mobility may be maximally increased at levels distant from the index level [7]. In addition, kyphotic deformity 
following $\mathrm{ACDF}$ has been implicated in the development of segmental instability, clinically significant ALD and poor functional recovery. It has been speculated that fusion in kyphosis increases posterior slipping forces onto adjacent vertebral levels and may cause higher loads on the posterior column than a fusion in lordosis [8].

Cervical disk arthroplasty cannot systematically supplant arthrodesis [9], but it has emerged as a promising alternative to fusion in appropriately selected patients [10] to reduce or eliminate ALD by preserving motion at the treated level.

The primary goals of the procedure are to preserve or to restore normal spinal kinematics. Nevertheless, although the range of motion (ROM) is an important feature of an artificial disk, it is only a single aspect of spinal biomechanics: elastic resistance to movement, twisting potential and elastic resistance to load bearing are major properties of the anatomical disk. Normal kinematics should not be analyzed only as a movement on the three planes, but also as elastic resistance to dynamic stress on these three planes.

The aim of motion preservation is also to neutralize excessive movements while preserving the physiologic biomechanical properties of the functional spinal unit (FSU) involved to interrupt the progression of degenerative processes and to prevent ALD. Elastic resistance of the FSU is a biomechanical property often underestimated but crucial for the stability of the spine. The biomechanics of cervical implants takes into account only the ROM of the devices and not the elastic resistance: the risk is a greater ROM in comparison with a normal disk, especially in rotation, with a potential overloading of the facet joints [11].

In terms of the quality of vertebral motion, the instantaneous center of rotation (ICR) during flexion-extension is considered as a major parameter. The ICR location depends on the cervical FSU level. In addition, Liu et al. described a correlation with the age-related degeneration [12]. Cervical arthroplasty should be optimized or adaptive enough for attempting an ICR location close to physiologic kinematic conditions of the motion segment according to physiologic aging, normal degenerative changes and local potential evolution.

The effect of this motion-sparing alternative on angulation at the treated level and on the overall spinal alignment may be important to long-term clinical outcomes and rates of adjacent segment disease. The control of stability and ROM is critical to optimize and maintain local and regional balance.

In addition, the impact on axial loading and shock absorption of the FSU needs to be addressed [13]. Successful reproduction of physiologic kinematics and longterm viability of the disk replacement must consider multiple factors, including facet loading, disk height, device design and biomaterials, and implant position [14]. The goal is to obtain the potential to approximate the axes of rotation of the native segment in flexion-extension, lateral bending and axial rotation, and a graded resistance to motion.

Total disk arthroplasty devices can be classified according to modular versus nonmodular design, fixation properties, articular design and composition (uniarticular, biarticular and nonarticular), and kinematics (constrained, semiconstrained and unconstrained) $[15,16]$.

The viscoelastic cervical disk prosthesis ESP is an innovative one-piece deformable but cohesive interbody spacer. It is an evolution of the LP ESP lumbar disk implanted since 2006 [17].

Recognizing that the human disk does not work like a joint but as a "silent bloc," this technology meets a critical need: in the cervical spine, the shock absorption and the control of stability are very important to avoid side-level degeneration, hypermobility and rotational or sagittal imbalance. In addition, the biomechanical constrains are very different from a disk level to each other as far as mobility is concerned. Moreover, one-third of the asymptomatic population has cervical kyphosis [18], and recent literature has pointed out significant modifications of the ICR according to the age and the degree of cervical degeneration [12]. The complexity of these anatomical and functional data shows the limitations of conventional mechanical prostheses and highlights the potential interest of viscoelastic concept for cervical prostheses.

CP ESP provides six full degrees of freedom about the three axes including shock absorption.

The prosthesis geometry allows limited rotation and translation with resistance to motion (elastic return property) aimed at avoiding overload of the posterior facets. The rotation center can vary freely during motion. It thus differs substantially from current prostheses.

The goal of this paper is to present this innovative concept and the preliminary clinical results and radiological outcomes. This study reports the results of a prospective pilot evaluation of the first patients implanted since 2012 . In addition to measuring ROM, we were specifically interested in the quality of the kinematics and thus we investigated the mean center of rotation at both the instrumented and adjacent levels.

\section{The implant}

Because the healthy human intervertebral disk has a deformable elastic structure with six degrees of freedom, elastomeric one-piece intervertebral prostheses might be the most physiologic implant for mimicking physiologic levels of shock absorption and flexural stiffness. The ESP ${ }^{\circledR}$ 
concept (currently lumbar and cervical disk prostheses marketed as the elastic spine pad) was in development for 20 years. With the technological advancements of the $\mathrm{ESP}^{\circledR}$, the problem of how to bond the elastic component and the titanium endplates of the disk is solved. Following promising in vitro and in vivo testing, the LP ESP gained clinical approval for use in Europe in 2005 for the lumbar levels [19]. More recently, the cervical version has been CE approved in 2012 for the first implantations.

The design of the CP ESP $^{\circledR}$ prosthesis is based on the principle of the silent block bush (Fig. 1). The CP ESP ${ }^{\circledR}$ is a one-piece deformable implant including a central core made of polycarbonate urethane (PCU) securely fixed to titanium endplates. The endplates have anchoring pegs to provide primary fixation and are covered by a textured T 40 titanium layer and hydroxyapatite to improve bone ongrowth. This center cushion is bonded to the titanium alloy endplates via adhesion molding and employs a peripheral groove without using glue for reinforcement. This type of fixation prevents fluid infiltration and fatigue fractures of the interface, despite the disparate mechanical properties of the polymer and metal endplates. The shape of the cushion has been studied to obtain an optimization of the mobility as well as the control of translation and shear movements during cervical spine mobility.

The PCU annulus is stabilized by supplementary "male" and "female" inner pegs located on the internal surface of both metal endplates. The geometry and position of the pegs, between the peripheral groove and the central area of the endplates, were planned to control compression and translation (Fig. 2). These two pegs, with their contactless fit of the male and female caps, serve to limit shearing during anteroposterior and medio-lateral translation. Through this mechanism, as well as crushing the annulus between the metal plates, the inner pegs also provide cushioning and compressing. These pegs also limit shearing when the endplates are inclined to the horizontal.

The prostheses are available in three thicknesses $(5,6$ and $7 \mathrm{~mm}$ ), each with three sizes in AP and lateral dimensions $(13 \mathrm{~mm} \times 15 \mathrm{~mm}, \quad 14 \mathrm{~mm} \times 17 \mathrm{~mm}$ and $15 \mathrm{~mm} \times 20 \mathrm{~mm}$ ). Regardless of the model, however, the mechanically active cushion and the mechanical properties of the prosthesis are the same: the differences in thickness do not affect the prosthesis's mobility or its cushioning, even shock-absorbing, effect. The design of the prosthesis allows a range of $14^{\circ}$ for flexion-extension, $12^{\circ}$ for rightleft lateral bending and $8^{\circ}$ for rotation. In addition, a
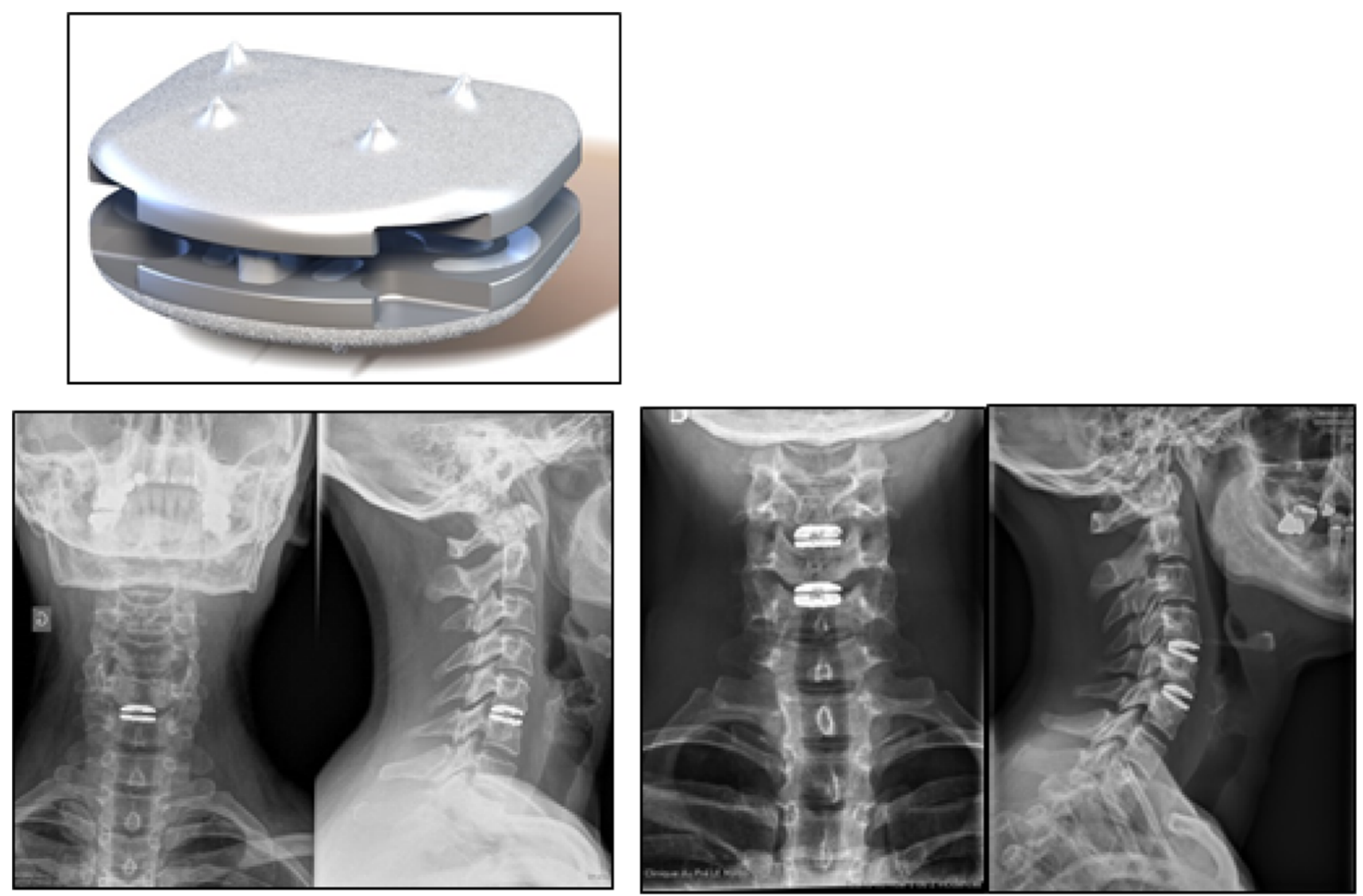

Fig. 1 Radiological images with CP ESP disk implant 
Fig. 2 Description of the implant

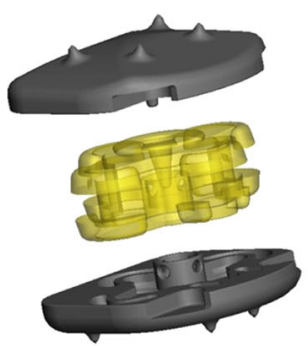

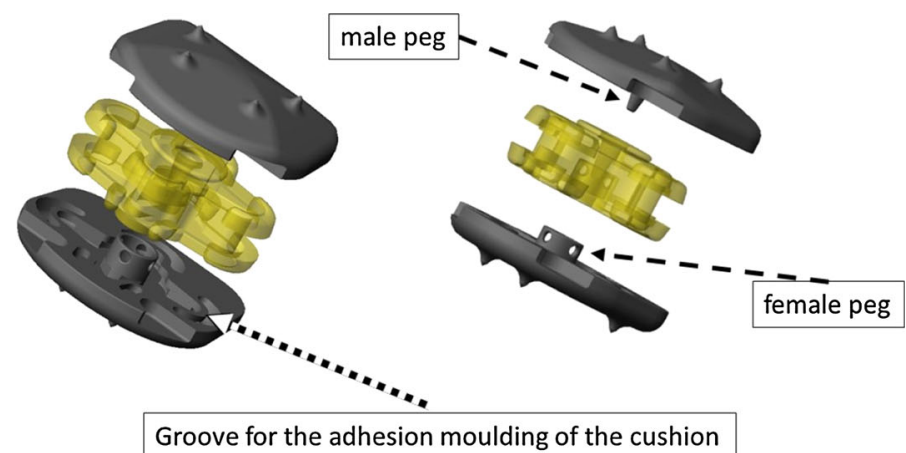

Table 1 Comparison of the characteristics of the CP ESP implants and normal cervical disk as reported in the literature

\begin{tabular}{lll}
\hline & CP ESP & Natural disk \\
\hline Stiffness for compression & $733 \mathrm{~N} / \mathrm{mm}$ & $492 \mathrm{~N} / \mathrm{mm}$ \\
Moment for extension & $0.03 \mathrm{Nm} / 1^{\circ}$ & $0.5 \mathrm{Nm} / 1^{\circ}$ \\
Moment for flexion & $0.03 \mathrm{Nm} / 1^{\circ}$ & $0.03 \mathrm{Nm} / 1^{\circ}$ \\
Moment for lateral bending & $0.05 \mathrm{Nm} / 1^{\circ}$ & $0.9 \mathrm{Nm} / 1^{\circ}$ \\
Moment for rotation & $0.24 \mathrm{Nm} / 1^{\circ}$ & $0.8 \mathrm{Nm} / 1^{\circ}$ \\
\hline
\end{tabular}

0.8-mm AP translation is possible. Overall, the principle of the $\mathrm{CP} \mathrm{ESP}^{\circledR}$ makes it possible to reproduce the anisotropy of the healthy disk, and the design allows the control of translation and of return torque.

\section{Mechanical properties}

The CP $\operatorname{ESP}^{\circledR}$ prosthesis, with its "silent block bush" system, improves upon fixed centers of rotation present in other, implants with an articulated design [20]. Additionally, for each direction requested, the CP ESP ${ }^{\circledR}$ prosthesis offers resistance that becomes greater with the amplitude of the movement. Thus, the CP ESP ${ }^{\circledR}$ is not directly comparable to the older first-generation implants. As a thirdgeneration prosthesis, it exhibits six degrees of freedom while offering a cushioning effect and restoring elasticity. The mechanical attributes of CP ESP approach those reported in the literature for a normal human disk. Rather than focusing on the global mobility of the implant, the research studies have addressed the reconstitution of the stiffness for the different mobility sectors expressed as bending and rotational moments (Table 1).

\section{Biomechanical assessment: fatigue and wear tests}

The originality of the concept of the $\mathrm{ESP}^{\circledR}$ prosthesis led to innovative and intense testing of various sorts. Wear tests were conducted in a three-axis motion simulator according to the ISO 18192 Norm (Fig. 3). Different configurations have been tested regarding the location of the rotation centers to address the worst case scenarios during the tests (Fig. 4). According to the different protocols, the loss of height ranged from 0.02 to $0.12 \mathrm{~mm}$ after 10 million cycles. No particles were detected in the water bath. As a comparison, the literature reports a loss of height of up to $0.02 \mathrm{~mm} / \mathrm{million}$ cycles for the Bryan disk. For this implant, the amount of particles has been reported as $0.96 \mathrm{~mm}^{3} /$ million cycles.

The mean loss of weight reported for the Bryan disk has been $6 \mathrm{mg} / \mathrm{million}$ cycles. In our testing protocol, the mean variation of weight has been $0.8 \mathrm{mg}$ for 10 million cycles for the CP ESP. Comparison with other implants is reported in Table 2. In addition, the alignment of the superior and inferior endplates has been studied after these series of tests to assess the cohesion of the cushion and metal parts. After 10 million cycles, the variation was insignificant $(0,2 \mathrm{~mm}$ for $\mathrm{AP}$ and lateral measurements).

\section{Structural tests: validation of the final stage of coating on the exterior side of the metal plates}

Adding a further final coating of porous titanium and spraying hydroxyapatite on the implant in its permanent form cause its temperature to rise. To ascertain the effect of this temperature increase on the flexible center cushion (at $120{ }^{\circ} \mathrm{C}$, there is a known risk of PCU deterioration), tests were conducted. The tests verified that the temperature rise did not affect the structure of the PCU.

\section{Biostability tests}

To evaluate the biostability of the ESP after conducting a wear test of 10 million cycles, we used a demineralized water bath and analyzed the particles collected during filtration. This method is consistent with the ISO standard 10993-13/biological evaluation of medical devices, Part 13: Identification and quantification of the decay products 
Fig. 3 Description of the cycle testing according to ISO 18192 Norm

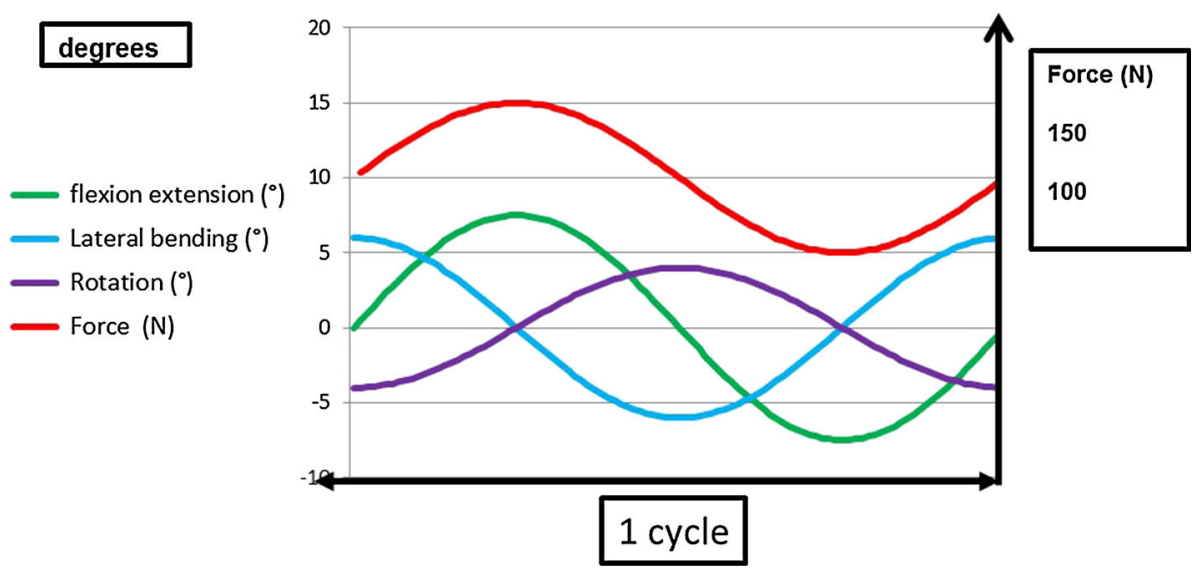

Fig. 4 Different configurations have been tested regarding the location of the rotation centers to address the worst case scenarios during the tests

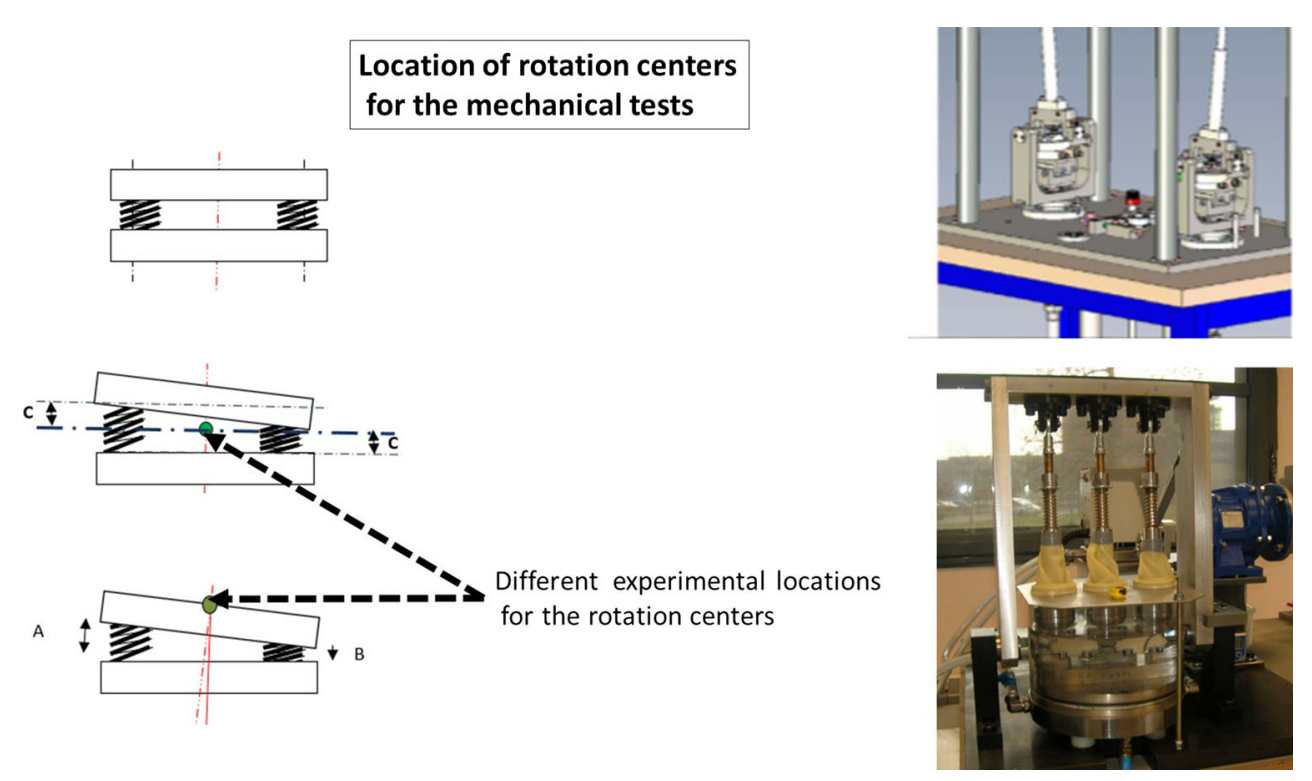

of polymer-based medical devices. We used a scanning electron microscope (SEM LEO I455VP), equipped with an energy-selective spectrometer (EDS OXFORD). No particles from the component materials of the prosthesis were found. These results were consistent with previous studies on the LP ESP disk.

\section{PCU aging test}

The specific PCU used for the LP ESP prosthesis is not oxidized during storage (bionate 80A (DSNM Biomedical, The Netherlands) according to master file MAF844) [28].

To evaluate this claim, the PCU was artificially aged in $80{ }^{\circ} \mathrm{C}$ water, in accordance with recommendations for aging plastics such as the UHMWPE (ASTM standard F 2003: Accelerated aging of ultra-high molecular weight polyethylene after gamma irradiation in air). The aged
PCU was then subjected to compression loads from $150 \mathrm{~N}$ to $1250 \mathrm{~N}$, consistent with ISO standard 18192 (intervertebral spinal disk prostheses Part 1: Loading and displacement parameters for wear testing and corresponding environmental conditions for test) for wear tests, for 10 million cycles.

No modification of the Fournier transform infrared spectrum or any modification of the mean molecular weight (ASTM standard D 5296) was observed. The PCU aging test results were comparable to those reported in the literature [29].

\section{Biocompatibility tests}

Biomatech (Chasse-sur-Rhone, France) conducted the biocompatibility tests (Table 3). The material components were evaluated individually and as a finished assembly, as 


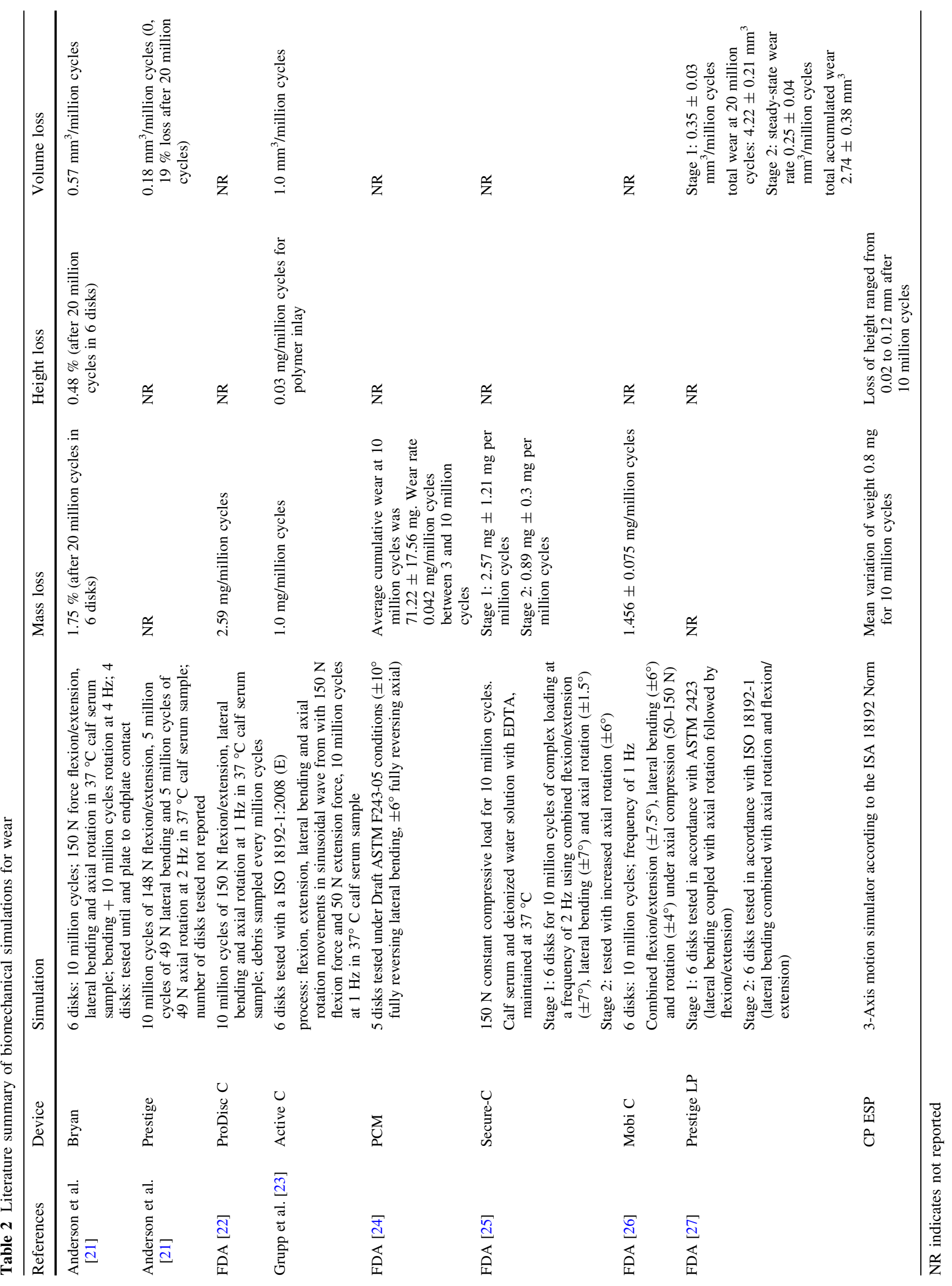


Table 3 Biocompatibility tests for CP ESP

\begin{tabular}{lll}
\hline Tests & Results & Standard \\
\hline $\begin{array}{l}\text { Mutagenicity } \\
\text { Chronic toxicity }\end{array}$ & Nonmutagenic & OECD N N71 $^{\circ}$ \\
ESP muscle implantation & Macroscopic reaction nonsignificant & ISO 10993-1 \\
Hemolysis & Nonhemolytic & ISO 10993-4 \\
Humoral immunological study & No humoral (serological) immune response & OECD N 407 \\
ESP pyrogenicity & Nonpyrogenic & ISO 10993-11 \\
Sensitization & No dermal sensitization & ISO 10993-10 \\
Acute systemic toxicity & No significant systemic toxicity & ISO 10993-11 \\
ESP implantation & Macroscopic reaction not significant & ISO 10993-6 \\
7 days in rabbits & & \\
Intracutaneous toxicity & No significant toxicity or irritation & ISO 10993-10 \\
Carcinogenicity & Noncarcinogenic & ISO 10993-3 \\
2 years in rats & & \\
\hline
\end{tabular}

specified in ISO standard 10993 (Biological Evaluation of Medical Devices): Cytotoxicity was assessed using ISO standard 10993-5. Testing for sensitization conformed to ISO standard 10993-10.

Employing ISO standard 10993-10, the components and assembly were tested for irritation or intradermal reaction. In addition, acute systemic toxicity was examined using ISO standard 10993-11 Chromosomal genotoxicity (Hearts test), and chromosomal anomalies were tested in accordance with ISO standard I 0993-3.

The Biomatech biocompatibility testing revealed that the ESP devices also satisfy the criteria of the FDA's subacute sensitization test (FDA-Guidelines for Toxicity Tests Chapter IV).

\section{Clinical study}

Our evaluation program was organized in two stages:

- a preliminary study with 1-year follow-up to detect potential dysfunctions and early postoperative stabilization problems or adjustment difficulties

- a 2-year analysis focused on radiological progression in terms of mobility and centers of rotation of analysis

\section{The cases}

We analyzed prospectively 62 consecutive cases included in a preliminary study according to the classical indications and contraindications for cervical disk replacement. The aim of this work is to provide a snapshot of the evolution of our series since the first implantations.

The surgeries were performed by two senior surgeons. There were 39 women and 23 men in this group. The average age was $45 \pm 8$ years (29-60). The implantation
Table 4 Description of the pilot study

\begin{tabular}{llcl}
\hline & Operated levels & Patients & CP ESP implants \\
\hline 1 level & C3C4 & 1 & 53 (74\% of the implants) \\
& C4C5 & 4 & \\
& C5C6 & 26 & \\
& C6C7 & 20 & \\
& C7D1 levels & 2 & \\
& C4C5/C5C6 & 2 & 18 (26\% of the implants) \\
& C5C6/C6C7 & 6 & \\
& C6C7/C7D1 & 1 & \\
& & & 71 implants \\
\hline
\end{tabular}

was on a single level in $74 \%$ of the CP ESP and on two levels in $26 \%$. Globally, 71 CP ESP prostheses were analyzed (Table 4).

Clinical data and X-rays were collected at the preoperative time and at 3, 6, 12 and 24 months post-op.

The functional results were measured using Neck and Arm VAS, NDI, SF-36 (physical component PCS and mental component MCS). The analysis was performed by a single observer who was independent from the selection of patients and from the surgical procedure.

\section{One-year follow-up results}

The mean operative time was $48 \mathrm{~min}(40-75 \mathrm{~min})$ (SD $9 \mathrm{~min}$ ). The hospital stay was 3.2 days (SD 0.8 ) (1-5 days).

We did not observe device-related specific complications. In this series, we did not face misalignment, instability or ossifications.

All clinical outcomes significantly improved at every time points when compared to the preoperative status (Table 5). Table 6 summarizes the changes in the variations of ROM over time. 
Table 5 Clinical outcomes of the preliminary study
Table 6 Evolution of the ROM of the implanted and adjacent levels

\begin{tabular}{|c|c|c|c|c|}
\hline Mean \pm SD & Pre-op & 3 Months & 6 Months & 12 Month \\
\hline \multicolumn{5}{|l|}{ (a) } \\
\hline VAS neck (/10) & 6 & 2.65 & 1.74 & 2.65 \\
\hline VAS arm (/10) & 6.3 & 2.7 & 1.8 & 2.4 \\
\hline NDI $(\%)$ & $56 \pm 16$ & $32.7 \pm 17$ & $22.1 \pm 16$ & $24 \pm 17$ \\
\hline NDI points & $27.4 \pm 8.8$ & $16.2 \pm 8.6$ & $10.9 \pm 7.9$ & $11.9 \pm 8.5$ \\
\hline SF-36 PCS score & 31 & 48 & 61 & 56 \\
\hline \multirow[t]{2}{*}{ SF-36 MCS score } & 32 & 50 & 63 & 62 \\
\hline & & $\begin{array}{l}\text { Pre-op/3 } \\
\text { Months }\end{array}$ & $\begin{array}{l}\text { Pre-op/6 } \\
\text { Months }\end{array}$ & $\begin{array}{l}\text { Pre-op/12 } \\
\text { Months }\end{array}$ \\
\hline \multicolumn{5}{|c|}{ (b) Mann-Whitney test for the evolution of the clinical tests (VAS, NDI, SF-36 P, SF-36 M) } \\
\hline \multirow[t]{2}{*}{ VAS neck } & Conclusion & & & \\
\hline & $P$ value & 0.01 & 0.01 & 0.01 \\
\hline \multirow[t]{2}{*}{ VAS arm } & Conclusion & & & \\
\hline & $P$ value & 0.01 & 0.01 & 0.01 \\
\hline \multirow[t]{2}{*}{ NDI } & Conclusion & & & \\
\hline & $P$ value & 0.01 & 0.01 & 0.01 \\
\hline \multirow[t]{2}{*}{ SF-36 PCS } & Conclusion & & & \\
\hline & $P$ value & 0.01 & 0.01 & 0.01 \\
\hline \multirow[t]{2}{*}{ SF-36 MCS } & Conclusion & & & \\
\hline & $P$ value & 0.01 & 0.01 & 0.01 \\
\hline
\end{tabular}

\begin{tabular}{lrrr}
\hline Degrees $\left(^{\circ}\right)$ & 3 Months & 6 Months & 12 Months \\
\hline ROM of the instrumented level & $6.8 \pm 4.1$ & $10.3 \pm 5.0$ & $8.4 \pm 4.3$ \\
ROM of the upper adjacent level & $9.7 \pm 4.9$ & $11.7 \pm 5.5$ & $12.9 \pm 6.8$ \\
ROM of the lower adjacent level & $6 \pm 4.1$ & $10 \pm 5.0$ & $9.4 \pm 5.7$ \\
\hline
\end{tabular}
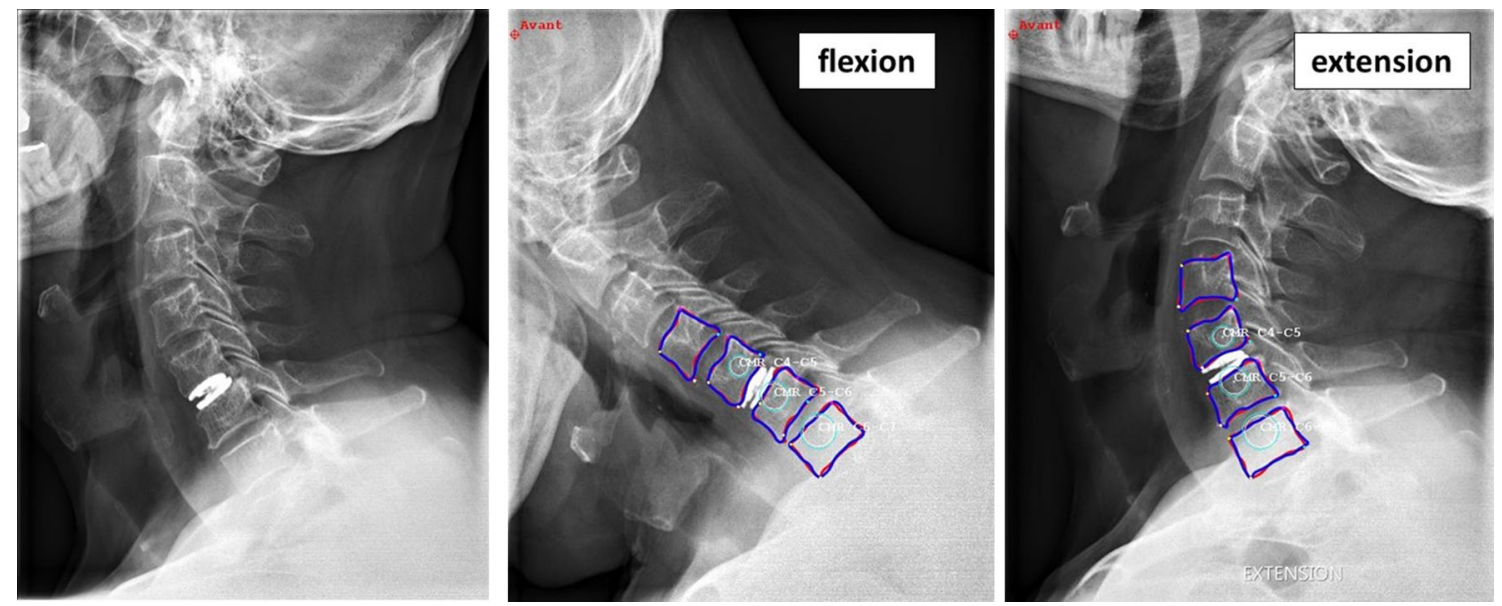

Fig. 5 Mean centers of rotation (MCR) at the instrumented and at the upper and lower adjacent levels measured for flexion/extension using Spineview ${ }^{\circledR}$ software; we can observe the adaptation of the implant including a translation for flexion

The mean centers of rotation (MCR) at the instrumented and at the upper and lower adjacent levels were measured in flexion/extension using Spineview ${ }^{\circledR}$ software (3-, 6- and 12-month follow-up) (Fig. 5). Their evolution illustrates the versatility and the forgiveness of the CP ESP implants according to the levels and the various sagittal balance. 


\section{Two-year follow-up results}

The evolution of clinical and radiological parameters confirms the good results already observed at 12 months of follow-up (Table 7; Fig. 6a-f).

Table 7 Clinical and radiological outcomes after 2-year follow-up

\begin{tabular}{ll}
\hline Mean \pm SD & 24 Months \\
\hline VAS neck (/10) & 2.9 \\
VAS arm (/10) & 1.6 \\
NDI (\%) & $19 \pm 17$ \\
NDI points & $9.3 \pm 8$ \\
SF-36 PCS score & 64.2 \\
SF-36 MCS score & 68.6 \\
ROM of the instrumented level & $10.7^{\circ} \pm 4.2^{\circ}$ \\
ROM of the upper adjacent level & $13.8^{\circ} \pm 6.5^{\circ}$ \\
ROM of the lower adjacent level & $11.1^{\circ} \pm 8.2^{\circ}$ \\
\hline
\end{tabular}

\section{Conclusion}

The design of the CP ESP ${ }^{\circledR}$ prosthesis provides stability by limiting rotation and translation, which prevents overload of the posterior facet joints. At the same time, the ESP center of rotation can fluctuate during motion. While achieving six degrees of freedom including vertical translation, this viscoelastic prosthesis also supplies cushioning, which offers shock absorption. The CP ESP thus distinguishes itself substantially from other current two- or threepiece prostheses that contain 1 or 2 bearing surfaces and provide only 3 or 5 degrees of freedom. These other devices also offer no or very little resistance and provide no elastic return. This study reports encouraging clinical results about pain, function, kinematic behavior and ROM. We concede that additional clinical studies and patient follow-up are needed to assess long-term reliability. However, the results we describe here suggest the outcomes that surgeons and patients might anticipate. (a)

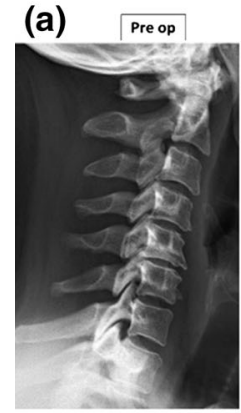

(c)

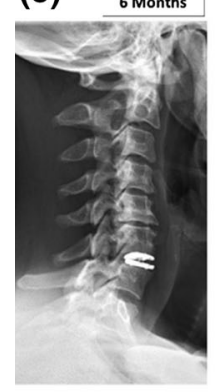

(e)

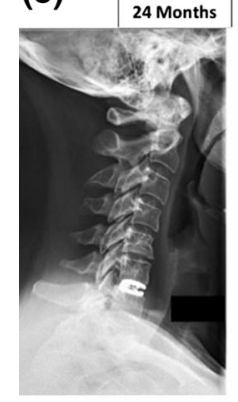

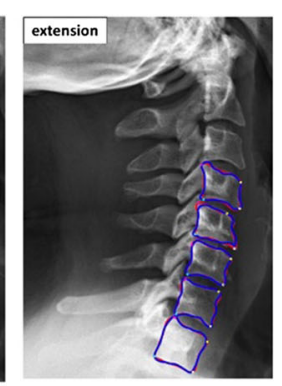
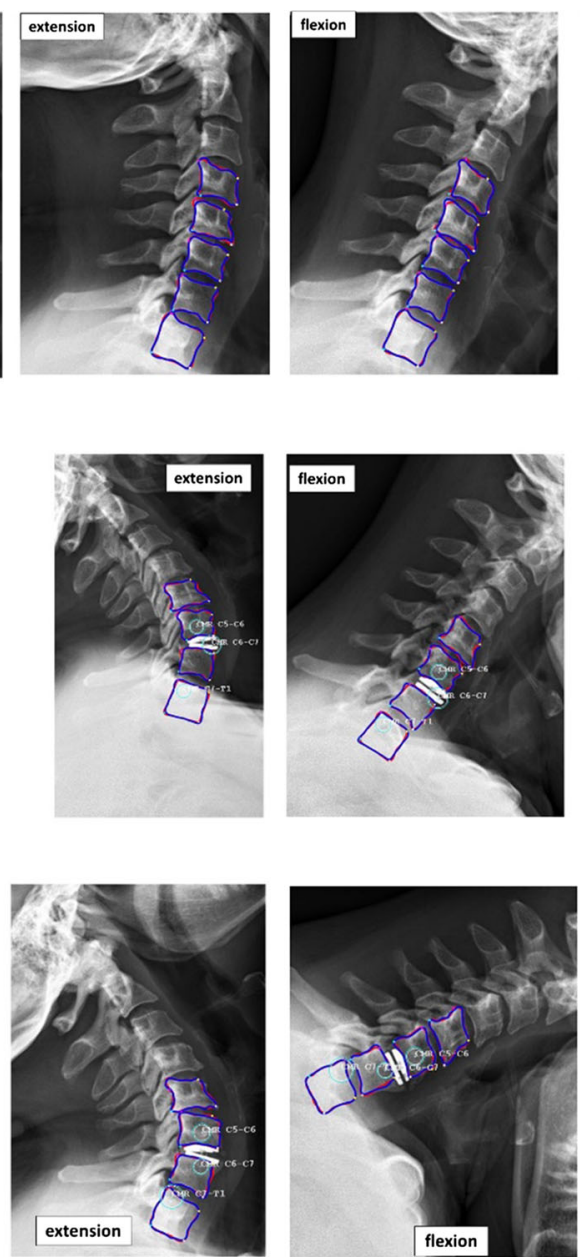

(b)

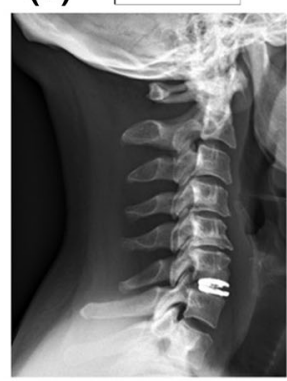

(d)

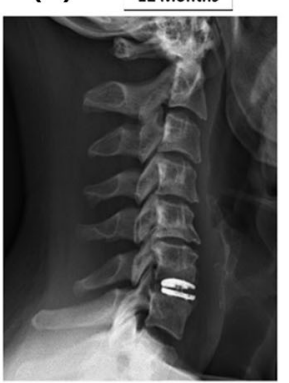

(f)
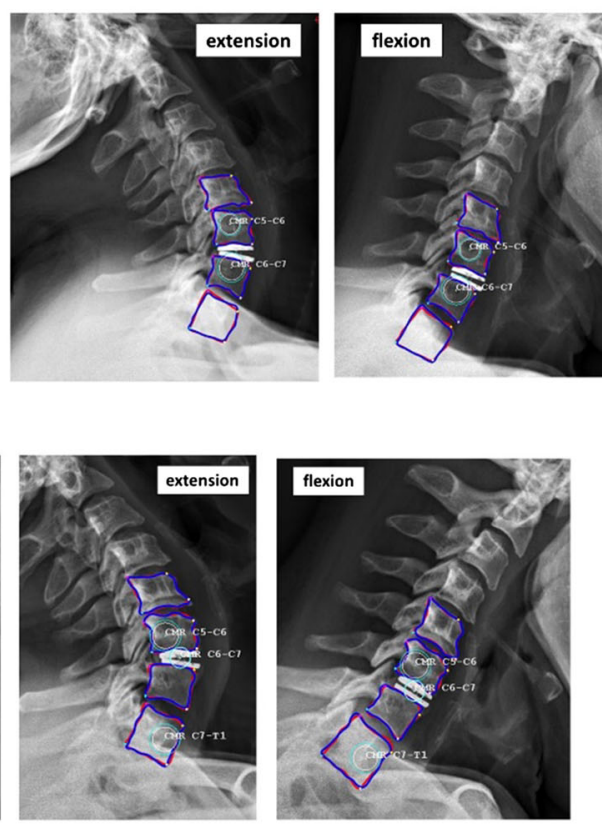

\begin{tabular}{llllll}
\hline & Pre op & 3M & $6 \mathbf{M}$ & $12 \mathrm{M}$ & 24M \\
\hline ROM of the instrumented level & $4^{\circ}$ & $9^{\circ}$ & $13^{\circ}$ & $10^{\circ}$ & $14^{\circ}$ \\
ROM of the upper adjacent level & $4^{\circ}$ & $10^{\circ}$ & $11^{\circ}$ & $11^{\circ}$ & $14^{\circ}$ \\
ROM of the lower adjacent level & $2^{\circ}$ & $5^{\circ}$ & $14^{\circ}$ & $12^{\circ}$ & $10^{\circ}$
\end{tabular}

Fig. 6 a-f Mean centers of rotation (MCR) and mobility at the instrumented and at the upper and lower adjacent levels in a patient with global cervical kyphosis: adaptation during the follow-up from 3 to 24 months 
The optimal ROM after TDR for limiting adjacent segmental disease has not yet been established. The radiological evaluation of the results is classically focused on the ROM, but the quality of movement is also an issue, especially at the cervical levels as coupled motions are a key point. The CP ESP acts as a deformable but cohesive interbody spacer that provides six full degrees of freedom about the three axes. This allows instantaneous axis of rotation change freely, as in the normal disk, which can optimize a functional coherence with the facet joints mechanics. It is also a significant benefit for the adaptation to the various disk levels as the biomechanical constrains are different from $\mathrm{C} 3$ to $\mathrm{T} 1$. Our preliminary experience did not point out complications as sagittal misalignment, ossifications and instability. An interesting point is the evolution of the MCR in the postoperative course. This adaptation ability is one of the main features of this promising implant as we need to consider the mean and long-term evolution of the global cervical posture and mobility after a cervical disk replacement.

\section{Compliance with ethical standards}

Conflict of interest No funding was received for this study. All of the authors are patent owners for disk replacement.

Human and animal rights All procedures performed in this study involving human participants were in accordance with the ethical standards of the institutional and/or national research committee and with the 1964 Helsinki Declaration and its later amendments or comparable ethical standards. Informed consent was obtained from all individual participants included in the study.

Open Access This article is distributed under the terms of the Creative Commons Attribution 4.0 International License (http://crea tivecommons.org/licenses/by/4.0/), which permits unrestricted use, distribution, and reproduction in any medium, provided you give appropriate credit to the original author(s) and the source, provide a link to the Creative Commons license, and indicate if changes were made.

\section{References}

1. Bartolomei JC, Theodore N, Sonntag VK (2005) Adjacent level degeneration after anterior cervical fusion: a clinical review. Neurosurg Clin N Am 16(4):575-587. doi:10.1016/j.nec.2005.07.004

2. Goffin J, Geusens E, Vantomme N, Quintens E, Waerzeggers Y, Depreitere B, Van Calenbergh F, van Loon J (2004) Long-term follow-up after interbody fusion of the cervical spine. J Spinal Disord Tech 17(2):79-85

3. Hilibrand AS, Carlson GD, Palumbo MA, Jones PK, Bohlman HH (1999) Radiculopathy and myelopathy at segments adjacent to the site of a previous anterior cervical arthrodesis. J Bone Joint Surg Am 81(4):519-528

4. Dmitriev AE, Cunningham BW, Hu N, Sell G, Vigna F, McAfee PC (2005) Adjacent level intradiscal pressure and segmental kinematics following a cervical total disc arthroplasty: an in vitro human cadaveric model. Spine (Phila Pa 1976) 30(10):1165-1172
5. Chang UK, Kim DH, Lee MC, Willenberg R, Kim SH, Lim J (2007) Range of motion change after cervical arthroplasty with ProDisc-C and prestige artificial discs compared with anterior cervical discectomy and fusion. J Neurosurg Spine 7(1):40-46. doi: 10.3171/SPI-07/07/040

6. Hwang SH, Kayanja M, Milks RA, Benzel EC (2007) Biomechanical comparison of adjacent segmental motion after ventral cervical fixation with varying angles of lordosis. Spine J 7(2):216-221. doi:10.1016/j.spinee.2006.05.018

7. Fuller DA, Kirkpatrick JS, Emery SE, Wilber RG, Davy DT (1998) A kinematic study of the cervical spine before and after segmental arthrodesis. Spine (Phila Pa 1976) 23(15):1649-1656

8. Katsuura A, Hukuda S, Saruhashi Y, Mori K (2001) Kyphotic malalignment after anterior cervical fusion is one of the factors promoting the degenerative process in adjacent intervertebral levels. Eur Spine J 10(4):320-324

9. Auerbach JD, Jones KJ, Fras CI, Balderston JR, Rushton SA, Chin KR (2008) The prevalence of indications and contraindications to cervical total disc replacement. Spine J 8(5):711-716. doi:10.1016/j.spinee.2007.06.018

10. Albert TJ, Eichenbaum MD (2004) Goals of cervical disc replacement. Spine J 4(6 Suppl):292S-293S. doi:10.1016/j.spi nee.2004.07.023

11. Landi A (2013) Elastic resistance of the spine: why does motion preservation surgery almost fail? World J Clin Cases 1(4):134-139. doi:10.12998/wjcc.v1.i4.134

12. Liu B, Liu Z, VanHoof T, Kalala J, Zeng Z, Lin X (2014) Kinematic study of the relation between the instantaneous center of rotation and degenerative changes in the cervical intervertebral disc. Eur Spine J 23(11):2307-2313. doi:10.1007/s00586-0143431-7

13. Kim SW, Shin JH, Arbatin JJ, Park MS, Chung YK, McAfee PC (2008) Effects of a cervical disc prosthesis on maintaining sagittal alignment of the functional spinal unit and overall sagittal balance of the cervical spine. Eur Spine J 17(1):20-29. doi:10. 1007/s00586-007-0459-y

14. Galbusera F, Bellini CM, Brayda-Bruno M, Fornari M (2008) Biomechanical studies on cervical total disc arthroplasty: a literature review. Clin Biomech (Bristol, Avon) 23(9):1095-1104. doi:10.1016/j.clinbiomech.2008.06.002

15. Fekete TF, Porchet F (2010) Overview of disc arthroplasty-past, present and future. Acta Neurochir (Wien) 152(3):393-404. doi:10.1007/s00701-009-0529-5

16. Stanton P, Eck JC (2010) Materials and design characteristics of cervical arthroplasty devices. Techniques in Orthopaedics 25(2):93-96. doi:10.1097/BTO.0b013e3181df2ef3

17. Lazennec JY, Aaron A, Brusson A, Rakover JP, Rousseau MA (2013) The LP-ESP $((\mathrm{R}))$ lumbar disc prosthesis with 6 degrees of freedom: development and 7 years of clinical experience. Eur $\mathrm{J}$ Orthop Surg Traumatol 23(2):131-143. doi:10.1007/s00590-0121166-X

18. Le Huec JC, Demezon H, Aunoble S (2015) Sagittal parameters of global cervical balance using EOS imaging: normative values from a prospective cohort of asymptomatic volunteers. Eur Spine J 24(1):63-71. doi:10.1007/s00586-014-3632-0

19. Lazennec JY, Even J, Skalli W, Rakover JP, Brusson A, Rousseau MA (2014) Clinical outcomes, radiologic kinematics, and effects on sagittal balance of the 6 df LP-ESP lumbar disc prosthesis. Spine J 14(9):1914-1920. doi:10.1016/j.spinee.2013. 11.016

20. Rousseau MA, Cottin P, Levante S, Nogier A, Lazennec JY, Skalli W (2008) In vivo kinematics of two types of ball-andsocket cervical disc replacements in the sagittal plane: cranial versus caudal geometric center. Spine (Phila Pa 1976) 33(1):E6E9. doi:10.1097/BRS.0b013e31815e5dce 
21. Anderson PA, Rouleau Jeffrey P, Toth Jeffrey M, Daniel Riew K (2004) A comparison of simulator-tested and -retrieved cervical disc prostheses. J Neurosurg Spine 1(2):202-210. doi:10.3171/ spi.2004.1.2.0202

22. Food and Drug Administration FDA (2009) Summary of safety and effectiveness data, ProDisc-C total disc replacement, P070001, 17 Dec 2007. http://www.accessdata.fda.gov/cdrh_ docs/pdf7/P070001b.pdf

23. Grupp TM, Meisel HJ, Cotton JA, Schwiesau J, Fritz B, Blomer W, Jansson V (2010) Alternative bearing materials for intervertebral disc arthroplasty. Biomaterials 31(3):523-531. doi:10. 1016/j.biomaterials.2009.09.064

24. Food and Drug Administration FDA (2012) Summary of safety and effectiveness data, PCM disc replacement, P100012, 26 Oct 2012. http://www.accessdata.fda.gov/cdrh_docs/pdf10/P100012b.pdf

25. Food and Drug Administration FDA (2012) Summary of safety and effectiveness data, Secure-C total disc replacement, P100003, 28 Sept 2012. http://www.globusmedical.com/pdf/secure-c/SSED.pdf
26. Food and Drug Administration FDA (2013) Summary of safety and effectiveness data, Mobi C total disc replacement, P110002, 7 Aug 2013. http://www.accessdata.fda.gov/cdrh_docs/pdf11/ P110002b.pdf

27. Food and Drug Administration FDA (2014) Summary of safety and effectiveness data, Prestige LP cervical disc replacement, P090029, 24 July 2014. http://www.accessdata.fda.gov/cdrh_ docs/pdf9/P090029b.pdf

28. Kurtz SM, Siskey R, Reitman M (2010) Accelerated aging, natural aging, and small punch testing of gamma-air sterilized polycarbonate urethane acetabular components. J Biomed Mater Res B Appl Biomater 93(2):442-447. doi:10.1002/jbm.b.31601

29. Christenson EM, Dadsetan M, Wiggins M, Anderson JM, Hiltner A (2004) Poly(carbonate urethane) and poly(ether urethane) biodegradation: in vivo studies. J Biomed Mater Res A 69(3):407-416. doi:10.1002/jbm.a.30002 